\title{
Proximal Humeral Fractures: Nonoperative Versus Operative
}

\section{Treatment}

\author{
Michiel G.J.S. Hageman, ${ }^{1}$ Diederik Meijer, ${ }^{2}$ Sjoerd A. Stufkens, ${ }^{3}$ David Ring, ${ }^{4}$ Job N. Doornberg, ${ }^{5,}$ and E.
}

Ph. Steller 6

${ }^{1}$ Research Fellow, Sint Lucas Andreas Ziekenhuis Amsterdam, PhD Research Fellow Orthopedic Hand and Upper Extremity Service, Massachusetts General Hospital, Yawkey Center, Suite 2100, 55 Fruit Street, Boston, MA 02114, USA

${ }^{2}$ Research Fellow, Department of Surgery, Sint Lucas Andreas Ziekenhuis Amsterdam, The Netherlands

${ }^{3}$ Resident, Academic Medical Center Amsterdam, University of Amsterdam Orthopedic Residency Program, PhD Research Fellow, Orthotrauma Research Center Amsterdam, The Netherlands

${ }^{4}$ Associate Professor of Orthopedic Surgery, Harvard Medical School, Orthopedic Hand and Upper Extremity Service, Massachusetts General Hospital, Yawkey Center, Suite 2100,55 Fruit Street, Boston, MA 02114, USA

${ }^{5}$ Resident, Sint Lucas Andreas Ziekenhuis Amsterdam, University of Amsterdam Orthopedic Residency Program, Postdoc Research Fellow, Orthotrauma Research Center Amsterdam, Academic Medical Center Amsterdam, Meibergdreef 9, 1100 DD Amsterdam, The Netherlands

${ }^{6}$ Chief Department of General Surgery, Sint Lucas Andreas Ziekenhuis Amsterdam, Secretariaat C4, Jan Tooropstraat 164, 1061 AE Amsterdam, The Netherlands

"Corresponding author: Job N. Doornberg, Resident, Sint Lucas Andreas Ziekenhuis Amsterdam, University of Amsterdam Orthopedic Residency Program, Postdoc Research Fellow, Orthotrauma Research Center Amsterdam, Academic Medical Center Amsterdam, Meibergdreef 9, 1100 DD Amsterdam, The Netherlands, E-mail: jobdoornbergortho@gmail.com

Received 2016 February 25; Revised 2016 November 03; Accepted 2016 November 06.

\begin{abstract}
Background: Management of displaced proximal humeral fractures is subject of ongoing debate.

Objectives: We aimed to review our results of operative treatment of proximal humeral fractures compared to age-, sex, and fracture-type controlled conservative treatment. We hypothesized that there is no significant difference in upper-extremity specific disability between patients treated with operative fixation and patients treated nonoperatively after displaced proximal humeral fracture. Our secondary null hypotheses were that there were no differences in pain intensity, satisfaction and physical function.

Methods: Thirty-three patients treated with operative fixation were enrolled and randomly matched with 33 patients treated nonoperatively according to age (within 5 years), sex, ASA-score, Neer fracture type and mechanism of injury. The patients were evaluated using the disabilities of the arm, shoulder and hand (DASH) scale, the constant score, short form (SF)-36 health survey, CESD, the pain catastrophizing scale (PCS) and pain intensity and satisfaction questionnaires.

Results: At follow-up, the nonoperatively treated patients had better functional outcomes than the operatively treated patients. Nonoperatively treated patients also scored better on pain intensity and satisfaction. There were no significant differences in CESD, PCS, and SF-36 physical- and mental health summary scores between cohorts.

Conclusions: The results of this study suggest that operative treatment might, on average, be detrimental to patients with proximal humeral fractures compared to natural healing. It will be a key to identify patients who will benefit from surgery.
\end{abstract}

Keywords: Proximal Humeral Fracture, Subcapital Humeral Fracture, Nonoperative Treatment, Operative Treatment

\section{Background}

Management of displaced proximal humeral fractures is subject of ongoing debate (1-4). The PROFHER randomized clinical trial recently showed no superiority of surgical over non-surgical treatment of adults with displaced fractures of the proximal humerus (4). Previous studies showed that the treatment of proximal humeral fractures largely depends on patient characteristics and surgeon's preferences and is not necessarily associated with fracture classification (5). For similar Neer types of 2-, 3- and 4- part fractures there are Level II and III studies supporting nonoperative treatment, open reduction and internal fixation using various techniques, and arthroplasty (6-9).

Data from randomized control trials are scarce and there is no consensus regarding the optimal treatment $(2$, $8,10,11)$. It has been shown that operative treatment in patients with displaced 3- and 4-part fractures leads to unpredictable results $(2,8,10,11)$. Adverse outcomes include implant failure, screw perforation, pain, and restricted abduction $(2,8,10,11)$. As a result, there is a need to further clarify the optimal intervention.

\section{Objectives}

In our parallel case-controlled retrospective study, we aimed to review our results of operative treatment of proximal humeral fractures compared to age-, sex, and fracture-type controlled conservative treatment. We studied matched retrospective cohorts of similar patients with similar fractures treated either operatively or nonoperatively to test the hypothesis that there is no significant difference in upper-extremity specific disability between patients treated with operative fixation and patients treated

Copyright (C) 2016, Kashan University of Medical Sciences. This is an open-access article distributed under the terms of the Creative Commons Attribution-NonCommercial 4.0 International License (http://creativecommons.org/licenses/by-nc/4.0/) which permits copy and redistribute the material just in noncommercial usages, provided the original work is properly cited. 
nonoperatively at final evaluation more than 6 months after injury. Our secondary null hypotheses were that there were no differences in pain intensity, satisfaction, normalized constant score, forward flexion, and abduction between cohorts. Finally, we analyzed factors associated with higher DASH scores, constant scores, pain intensity, and satisfaction.

\section{Methods}

\subsection{Study Design}

This was a retrospective case-control study to investigate differences in upper extremity specific disability between patients who were and were not operatively treated for a displaced proximal humerus fracture. Displacement was defined as displacement of $1 \mathrm{~cm}$ or $45^{\circ}$ of angulation between two fragments. After approval by our institutional review board, we used our hospital's billing records to search the hospital PACS (picture archiving communications system) database for patients with displaced fractures of the proximal humerus. Adult (age 18 or greater), Dutch speaking patients with an isolated displaced fracture of the proximal humerus between January 2004 and August 2011 and at least 6 months of follow-up and complete demographic information were eligible. Exclusion criteria were: 1) major musculoskeletal (pathological fracture) or neurological comorbidities (e.g. Parkinson disease, multiple sclerosis,); 2) open fracture; 3) treatment with arthroplasty; 4) cognitive impairment (e.g. dementia, head injury, overall illness) and 5) patients with pathological fractures or associated upper limb injuries.

We identified 558 patients with fractures of the proximal humerus. Four hundred and twenty-six patients were treated nonoperatively and 132 had operative fixation, including 73 patients treated with arthroplasty. Patients that had surgery more than 30 days after injury were categorized as nonoperatively treated.

\subsection{Characteristics of Patients with Operative Fixation}

Fifty-nine of the 132 operatively treated patients satisfied the inclusion and exclusion criteria. Among the 59 patients, 8 patients were deceased, 11 patients declined, resulting in a cohort of 40 patients. Among these 40 operatively treated patients, 3 (2.3\%) did not respond or could not be contacted after three written requests and three requests by phone, 4 patients could not be matched and, leaving a cohort of 33 patients available for the study.

Among these 33 patients there were 11 men and 22 women, with a mean age at follow-up of $59 \pm 13$ years. Fractures were classified according to the Neer classification, rated by two independent observers on the basis of anteroposterior and transscapular Y-view radiographs, two- and three-dimensional computed tomography, if applicable, and intraoperative fracture visualization obtained from operation notes. There were 19 two-part fractures, 11 threepart and 3 four-part fractures (12). Injury mechanisms included high-energy trauma in 13 patients and a fall from a standing height in 20 patients. The American Society of Anesthesiologists (ASA) classification was ASA-1 in 14 patients, ASA-2 in 13 patients, ASA-3 in 5 patients. Among these 33 patients 2 were treated with percutaneous K-wires, 5 with screws, 3 with intramedullary nails, and 23 with a locking plate and screws (Table 1).

\subsection{Matched Nonoperatively Treated Patients}

Each patient treated with operative fixation was randomly matched with a patient treated nonoperatively according to age (within 5 years), sex, ASA-score, Neer fracture type (2, 3 or 4 part), and mechanism of injury. Thirtyeight patients, who were matched for each patient that had operative fixation, were asked to consider participation. One patient declined participation (2.7 \%), 1 patient lived abroad (2.7\%), and 3 (8.1\%) patients did not respond or could not be contacted after three written and three phone requests.

The nonoperatively treated patients $(n=33)$ were evaluated a median of 5.8 (IQR: 4.1 - 6.6) years after the injury. The nonoperatively treated patients differed significantly compared to the operative fixation cohort for the duration of follow-up (5.8 vs. 3.1 years). The nonoperative group contained 2 patients more with type - 4 fractures than the operative fixation group (Table 1 ).

\subsection{Complications and Subsequent Procedures}

Five patients (15\%) in the operative cohort and two patients (6\%) in the nonoperative cohort had an unplanned second operation within twelve months of fracture. The five surgeries in the operative cohort included one patient with a deep infection; one patient that had surgery to revise a loose plate and screws 4 months after the surgery; and one patient that had repeat internal fixation of a displaced lesser tuberosity fragment 3 months after the original surgery; one patient that had a hemiarthroplasty for pain and stiffness related to osteonecrosis of the humeral head 17 months after surgery; and one patient that had surgery to address a defect in the supraspinatus that was felt to be causing stiffness and pain.

The two reoperations in the nonoperative cohort were an arthroplasty to address recurrent shoulder dislocation in one patient, and open reduction and internal fixation of a displaced greater tuberosity fracture in the other. 
Table 1. Patients' Characteristics

\begin{tabular}{|c|c|c|c|}
\hline & Nonoperative Group $(n=33)$ & Operative Group $(n=33)$ & P Value \\
\hline \multicolumn{4}{|l|}{ Gender (n, \%) } \\
\hline Male & $9(27.3)$ & $11(33.3)$ & 0.59 \\
\hline Female & $24(72.7)$ & $22(66.7)$ & \\
\hline Age at injury, years (mean, SD) & $60.1(15.3)$ & $59.0(12.5)$ & 0.74 \\
\hline Delay, days (mean, SD) & - & $13.8(8.1)$ & - \\
\hline Follow-up duration, years, (median, IQR) & $5.8(4.1 ; 6.6)$ & $3.1(2.3 ; 5.8)$ & 0.001 \\
\hline Smoking (n,\%) & $9(27.3)$ & $11(33.3)$ & 0.59 \\
\hline Diabetes (n, \%) & $7(21.2)$ & $5(15.2)$ & 0.52 \\
\hline Dominant arm affected (n, \%) & $16(48.5)$ & $14(42.4)$ & 0.62 \\
\hline \multicolumn{4}{|l|}{ ASA } \\
\hline ASA I & $10(30.3)$ & $14(42.4)$ & 0.49 \\
\hline ASA II & $19(57.6)$ & $14(42.4)$ & \\
\hline ASA III & $3(9.1)$ & $5(15.2)$ & \\
\hline ASA IV & $1(3.0)$ & & \\
\hline \multicolumn{4}{|l|}{ Neer Classification (n, \%) } \\
\hline 2 Part & $12(36.3)$ & $19(57.6)$ & 0.22 \\
\hline 3 Part & $16(48.5)$ & $11(33.3)$ & \\
\hline 4 Part & $5(15.2)$ & $3(9.1)$ & \\
\hline \multicolumn{4}{|l|}{ Fracture mechanism (n, \%) } \\
\hline Type I (Slipped) & $10(30.3)$ & $13(39.4)$ & 0.44 \\
\hline Type II (High energy trauma) & $23(79.7)$ & $20(60.6)$ & \\
\hline \multicolumn{4}{|l|}{ Osteosynthesis (n, \%) } \\
\hline Screws & - & $5(15.2)$ & - \\
\hline K-wires & - & $2(6.1)$ & \\
\hline Nail & - & $3(9.1)$ & \\
\hline ORIF & - & $23(69.6)$ & \\
\hline Revision (n, \%) & $2(6.1)$ & $5(15.2)$ & 0.43 \\
\hline
\end{tabular}

Abbreviations: ASA, the American society of anesthesiologists; ORIF, open reduction internal fixation.

There were two planned surgeries subsequent to the initial fracture surgery, both for removal of buried percutaneously inserted Kirschner wires.

\subsection{Evaluation}

When patients returned for a research visit, informed consent was obtained. Patients were examined and asked to complete a survey. The evaluations were performed by 2 independent observers that were not involved in the care of the patients.

The patients were evaluated using the Constant score (including measurement of motion and strength) and they completed the DASH, SF-36, CES-D, and PCS questionnaires. To analyze pain intensity, we used the five-point Likert measure of pain intensity. Patients rated their satisfaction with the outcome dichotomously (satisfied or not satisfied).

The Constant score is a 10-item physician-reported outcome inventory. The Constant score assess the patient's shoulder function from 0 to 100 . Score higher than 80 is rated as normal function, 70 - 80 as moderate function, and lower than 70 implies poor upper extremity-specific function. For missing values, mean imputation was used (13, 14). To determine the normalized Constant score the following formula was used: Normalized score $=$ (Raw score) 
Normal score) $\times 100$. The normal score for the denominator of the equation was obtained from the normalized values published by Katolik et al. Range of motion was measured in a standardized fashion with a hand-held goniometer by two independent observers not involved in the patients' care. For patients with contralateral injuries, normative measurements adjusted for age and gender were used as control (15). The muscle strength was measured with hand held weight, weighted $250 \mathrm{~g}$ each and compared with contralateral side. This measurement is recorded at $90^{\circ}$ of abduction in the scapular plane. Patient who were unable to achieve the test position were assigned a strength score of 0 .

The validated dutch form of the disabilities of the arm, shoulder and hand (DASH) questionnaire was used to assess upper extremity disability (16). The DASH is comprised of 30 questions, which each is answered on a 5-point Likert scale. Scores range between zero and one hundred points, a higher score indicating worse upper extremity-specific disability and pain. Using this computed result a scale's scores were calculated, ranging from 0 (no disability) to 100 (most severe disability) (16). To measure pain intensity we used question 24 of the DASH, which asks whether the patient has arm shoulder or hand pain during the last week.

The Dutch form of CES-D (CES-D-NL) was used to assess symptoms of depression in the past week (17-19). The center for epidemiological studies-depression (CESD) scale is a self-reported scale designed to measure self-reported depression (20). The questionnaire consists of 20 items associated with depression questions on a 4-point Likert Scale, ranging from "Rarely or none of the Time (Less than 1 day)" to "Most or all of the time (5-7 days)". Scores are summed to provide an overall score ranging from 0 to 60 , with a higher score indicating greater symptoms of depression. For missing values mean imputation was used (20).

The PCS was used to measure catastrophic thinking (18). The questionnaire consists of 13 questions answered on a 5-point Likert Scale, ranging from (0) "not at all" to 4 "all the time". Scores range from 0 to 52, with a higher score implying more catastrophic thinking. For missing values mean imputation was used (18).

The short form-36 health survey is a validated health survey (21). This is comprised of eight scaled scores (vitality, physical function, bodily pain, general health perceptions, physical role-, emotional role-, social role functioning, and mental health). We used the physical and mental component summary ranging from 0 - 100, with a higher score implying higher individual patients' health status.

Standardized anteroposterior and scapular Y radiographs of the injured shoulder were taken. The radiographs were evaluated by two independent observers (JND and SAS) for nonunion and fixation failure. The independent observers visited 5 patients, who were unable to visit the hospital, at home for clinical assessment (radiographs were not obtained in those 5 patients).

\subsection{Statistical Analysis}

Continuous data were checked for normality by use of the Shapiro-Wilk tests and presented as means with standard deviations (SD) when normally distributed, otherwise medians with interquartile ranges (IQR) were described. Mean imputation was used for 2 CESD-scores and one DASH that were not completed. Categorical data were described as frequencies with accompanying percentages. Comparisons of the patient characteristics between the treatment groups were made according to their distribution. In case of normality of continuous variables Student's t-tests were performed, otherwise nonparametric variants (the Mann-Whitney U tests) were used. For categorical data, Chi-square tests were performed. Due to skewed distributions and the ordinal character of the functional outcome measures (DASH, Constant score, and pain, respectively), analysis was performed nonparametrically (the Mann-Whitney U tests, and Kruskall- Wallis tests). Associations with other outcome measures were assessed by use of Spearman's correlation coefficients. Comparisons with respect to satisfaction were performed using the Chisquare or Fisher's exact tests (in case of expected counts less than 5). A P value less than 0.05 was considered statistically significant. The examination of differences between the operatively and nonoperatively treated patients was performed by a post-hoc analysis.

\section{Results}

Patients treated operatively had greater disability (a higher DASH score) on average compared to patients treated nonoperatively $(8.3(0.4 ; 22.1)$ vs. 19.0 (9.2; 37.9); P $<0.01$ ) (Table 2 ). There was a significant negative correlation of DASH with forward flexion $(\mathrm{r}=-0.73, \mathrm{P}<0.01)$ and abduction $(\mathrm{r}=-0.74, \mathrm{P}<0.01)$ (Tables 3 and 4$)$. There were also significant associations between DASH and age, CES-D, PCS, reoperation, and ASA (Tables 3 and 4).

The normalized Constant score was significantly higher in patients treated nonoperatively 89.0 (75.5; 98.0) compared to patients treated operatively (67.0 (40.0; 83.0); $\mathrm{P}<0.01$ ) (Table 2). Also, the Constant score was significantly correlated with forward flexion $(\mathrm{r}=0.85, \mathrm{P}$ $=<0.01$ ) and abduction $(\mathrm{r}=0.85, \mathrm{P}=<0.01$ ) (Tables 3 and 4 ). There was also a significant association between Constant score and the CES-D, reoperation and the type of osteosynthesis (Tables 3 and 4). 
Table 2. Clinical Outcome Measures

\begin{tabular}{|c|c|c|c|}
\hline & Nonoperative Group $(n=33)$ & Operative Group $(\mathbf{n}=33)$ & PValue \\
\hline \multicolumn{4}{|l|}{ Functional outcome (median, IQR) } \\
\hline DASH-standard & $8.3(0.4 ; 22.1)$ & $19.0(9.2 ; 37.9)$ & 0.007 \\
\hline Constant score (absolute) & $89.0(75.5 ; 98.0)$ & $67.0(40.0 ; 83.0)$ & 0.001 \\
\hline Constant score (normalized) & $100(90.2 ; 100)$ & $78.4(48.6 ; 97.1)$ & $<0.001$ \\
\hline Pain & $1(1.0 ; 2.8)$ & $2(1.0 ; 3.8)$ & 0.17 \\
\hline Anterior elevation, degrees & $170(133 ; 180)$ & $120(90 ; 165)$ & 0.005 \\
\hline Abduction, degrees & $160(120 ; 180)$ & $120(90 ; 165)$ & 0.008 \\
\hline \multicolumn{4}{|l|}{ Overall health outcome (median, IQR) } \\
\hline CESD & $4(0 ; 13)$ & $4(1.5 ; 8.5)$ & 0.86 \\
\hline PCS & $7(0 ; 15)$ & $5(0: 10)$ & 0.48 \\
\hline SF-36 PCS & $48.7(40.9 ; 55.4)$ & $47.0(34.6 ; 52.9)$ & 0.19 \\
\hline SF-36 MCS & $53.6(47.5: 57.5)$ & $54.3(44.8 ; 59.8)$ & 0.95 \\
\hline \multicolumn{4}{|l|}{ Satisfaction (n, \%) } \\
\hline Satisfied & $28(84.8 \%)$ & $19(57.6 \%)$ & 0.014 \\
\hline
\end{tabular}

Abbreviations: IQR, interquartile ranges; DASH, disabilities of arm, shoulder and hand; CESD, center for epidemiological studies-depression; PCS, the pain catastrophizing scale.

Table 3. Spearman Correlation Coefficients With Functional Outcome Measures

\begin{tabular}{|c|c|c|c|}
\hline & DASH & Constant Score (Normalized) & Pain Score \\
\hline Follow- up duration & $-0.28^{a}$ & $0.33^{\mathrm{a}}$ & -0.17 \\
\hline Age (at injury) & $0.29^{\mathrm{a}}$ & -0.17 & -0.17 \\
\hline ASA & $0.27^{\mathrm{a}}$ & -0.19 & 0.04 \\
\hline CESD & $0.29^{\mathrm{a}}$ & $-0.24^{\mathrm{a}}$ & $0.39^{\mathrm{a}}$ \\
\hline PCS & $0.28^{\mathrm{a}}$ & -0.16 & $0.36^{\mathrm{a}}$ \\
\hline Forward flexion & $-0.73^{\mathrm{a}}$ & $0.85^{\mathrm{a}}$ & $-0.45^{\mathrm{a}}$ \\
\hline Abduction & $-0.74^{a}$ & $0.85^{\mathrm{a}}$ & $-0.74^{\mathrm{a}}$ \\
\hline
\end{tabular}

Abbreviations: DASH, disabilities of arm, shoulder and hand; ASA, the American Society of Anesthesiologists; CESD, Center for Epidemiological Studies-Depression; PCS, the pain catastrophizing scale.

${ }^{\mathrm{a}} \mathrm{P}<0.05$

Pain intensity averaged $1(1.0 ; 2.8)$ after the operative fixation and $2(1.0 ; 3.8)$ after the nonoperative treatment (P $=0.17$ ) (Table 2 ). There was a positive correlation between pain intensity and CESD and PCS, and a negative correlation with forward flexion and abduction. (Table 3 and 4 )

Patients treated nonoperatively were significantly more satisfied (28 of 33 patients; $85 \%$ ) than patients treated with the operative fixation (19 of 33 patients; $58 \%$ ) (Table 2 ). Dissatisfaction was significantly associated with reoperation, and decreased forward flexion and abduction (Table 3 and 4).

The average forward flexion and abduction were both significantly greater in the nonoperative cohort. There were no significant differences in CESD, PCS, and SF-36 physical- and mental health summary scores between cohorts (Table 2 ).

\section{Discussion}

This retrospective comparative study of age, sex, ASA and fracture type matched patients showed that nonoperatively treated patients had better functional outcomes than the operatively treated patients. Nonoperatively treated patients also scored better on pain intensity and satisfaction. 


\begin{tabular}{|c|c|c|c|c|c|c|c|c|c|c|}
\hline & & DA & & Constant ( $\mathrm{N}$ & & $\mathrm{Pa}$ & & & Satisfied & \\
\hline & & Median (IQR) & P Value & Median (IQR) & PValue & Median (IQR) & PValue & Yes (No. \%) & No (No.\%) & P Value \\
\hline Gender & & & 0.57 & & 0.78 & & 0.27 & & & 0.30 \\
\hline & Male $(\mathrm{n}=20)$ & $14.1(2.7 ; 25.1)$ & & $95.1(76.7 ; 100)$ & & $1(1: 2)$ & & $16(80 \%)$ & $4(20 \%)$ & \\
\hline & Female $(n=46)$ & $14.7(4.1 ; 35.2)$ & & $90.2(66.7 ; 100)$ & & $2(1: 3)$ & & $31(67 \%)$ & $15(33 \%)$ & \\
\hline Smoking & behavior & & 0.42 & & 0.09 & & 0.15 & & & 0.19 \\
\hline & Smoker $(n=20)$ & $17.1(2.7 ; 45.1)$ & & $77.2(42.9 ; 100)$ & & $2(1: 3)$ & & $12(60 \%)$ & $8(40 \%)$ & \\
\hline & Nonsmoker $(n=46)$ & $11.7(4.2 ; 29.2)$ & & $95.1(77.8 ; 100)$ & & $1(1 ; 2)$ & & $35(76 \%)$ & $11(24 \%)$ & \\
\hline Diabetes & & & 0.14 & & 0.19 & & 0.53 & & & 0.73 \\
\hline & Diabetes $(n=12)$ & $26.3(11.9 ; 60.9)$ & & $75.3(47.5 ; 99.4)$ & & $2(1 ; 4)$ & & $8(67 \%)$ & $4(33 \%)$ & \\
\hline & Nondiabetes (54) & $11.5(2.9 ; 28.4)$ & & $94.4(74.5 ; 100)$ & & $2(1 ; 3)$ & & $39(72 \%)$ & $15(28 \%)$ & \\
\hline Dominan & t arm & & 0.51 & & 0.91 & & 0.69 & & & 0.07 \\
\hline & $\operatorname{Dominant}(\mathrm{n}=30)$ & $16.2(2.5: 44.0)$ & & $94.0(60.8 ; 100)$ & & $1(1: 3)$ & & $18(60 \%)$ & $12(40 \%)$ & \\
\hline & Nondominant $(\mathrm{n}=36)$ & $12.5(3.9 ; 27.3)$ & & $87.2(70.3 ; 100)$ & & $2(1 ; 3)$ & & $29(81 \%)$ & $7(19 \%)$ & \\
\hline Re-opera & tion & & 0.002 & & $<0.001$ & & 0.36 & & & 0.002 \\
\hline & Reoperation ( $\mathrm{n}=7$ ) & $41.7(27.5 ; 83.3)$ & & $42.0(8.3 ; 63.0)$ & & $2(1: 4)$ & & $1(14 \%)$ & $6(86 \%)$ & \\
\hline & No reoperation $(\mathrm{n}=59)$ & $11.7(2.5 ; 28.3)$ & & $95.5(76.1 ; 100)$ & & $2(1: 3)$ & & $46(78 \%)$ & $13(22 \%)$ & \\
\hline Fracture & type & & 0.83 & & 0.20 & & & & & 0.31 \\
\hline & $\operatorname{Part} 2(\mathrm{n}=31)$ & $16.7(3.4 ; 41.7)$ & & $87.7(54.2 ; 100)$ & & $2(1 ; 3)$ & 0.46 & $22(71 \%)$ & $9(19 \%)$ & \\
\hline & Part $3(n=27)$ & $12.5(4.6: 27.5)$ & & $97.5(79.1,100)$ & & $1.5(1: 3)$ & & $21(78 \%)$ & $6(22 \%)$ & \\
\hline & Part $4(n=8)$ & $16.8(0.0: 57.3)$ & & $78.4(46.3 ; 98.5)$ & & $1(1 ; 2)$ & & $4(50 \%)$ & $4(50 \%)$ & \\
\hline Osteosyn & th. Type & & 0.22 & & 0.24 & & 0.67 & & & 0.60 \\
\hline & $\operatorname{Screw}(\mathrm{n}=5)$ & $10.8(2.5 ; 17.1)$ & & $100(74.1 ; 100)$ & & $1(1 ; 2)$ & & $1(25 \%)$ & $4(75 \%)$ & \\
\hline & K-wires $(\mathrm{n}=2)$ & $32.5(7.5 ; 57.5)$ & & $68.7(37.4 ; 100)$ & & $2.5(1 ; 4)$ & & $1(50 \%)$ & $1(50 \%)$ & \\
\hline & $\operatorname{Nail}(\mathrm{n}=3)$ & $41.7(13.8 ; 91.7)$ & & $42.0(5.3 ; 77.1)$ & & $2(1 ; 4)$ & & $2(40 \%)$ & $3(60 \%)$ & \\
\hline & $\operatorname{ORIF}(\mathrm{n}=22)$ & $25.8(8.4: 34.2)$ & & $79.1(56.2 ; 90.7)$ & & $2(1 ; 3)$ & & $16(64 \%)$ & $9(36 \%)$ & \\
\hline
\end{tabular}

Abbreviations: DASH, disabilities of arm, shoulder and hand; IQR, interquartile ranges; ORIF, open reduction internal fixation.

This study should be interpreted in the light of the fact that we matched by age, ASA, injury mechanism, and fracture type, but we did not account for functional demands and the activity level. In addition, the findings may not be specific to the practice style of the surgeons in other centers. Although the results showed a significant difference for our primary outcome, the post- hoc analysis showed a moderate power (0.51) and an effect size of 0.53 . This inevitably raises the risk of obtaining a false positive (a Type I error). Another shortcoming is the difference in follow-up between both groups.

The finding that the nonoperatively treated patients have better outcomes than the operatively treated patients is in line with results of prior studies $(2,11)$. Zyto et al. performed a randomized study comparing nonoperative treatment versus tension-band osteosynthesis of displaced 3- or 4-part fractures of the humerus, which showed no significant difference at follow-up at 1, 3 and 5 years regarding functional differences between the two groups (2). Olerud et al. randomized elderly patients with displaced 3-part proximal humeral fractures to either internal fixation or nonoperative treatment and found no dif- ference in mean flexion (11). In another randomized control trial of hemiarthrosplasty compared to nonoperative treatment for displaced 4-part fractures of the proximal humerus demonstrated a significant advantage in quality of life among patients treated with arthroplasty, but no differences in motion (8). More recently the PROFHER randomized clinical trial showed no superiority of surgical over nonsurgical treatment of adults with displaced fractures of the proximal humerus (4).

The association between psychosocial factors and physical outcome and pain intensity is in accordance with previously reported literature. However, it was less strong with impairment (lack of abduction) rather than symptoms of depression or catastrophic thinking accounting for more of the variation in magnitude of disability and pain intensity.

The complication rate of operative and nonoperative treatment of proximal humeral fractures found in this study is comparable with prior studies where the rate has varied from $7 \%$ to $34 \%(7,11,22,23)$. Konrad et al. felt that $40 \%$ of the complications were related to technical deficiencies (24). In our series, 2 of the 5 patients that had a 
second surgery ( 2 of 33 overall in the operative treated cohort) had insufficient fixation.

The results of this study suggest that the trauma of operative treatment might, on average, be detrimental to patients with proximal humeral fractures compared to natural healing. It is certainly plausible that the work of cutting skin, splitting muscle and applying plates could impair the physical function, add complications, and affect symptoms, disability, and satisfaction. In our opinion, there are likely some patients with proximal humeral fractures who will benefit from surgery and the key is to learn how to identify these fractures.

The prospective randomized study is needed to rule out the bias of the treating trauma surgeon in selecting patients for operative treatment as well as conservative treatment.

\section{Acknowledgments}

M.G. Hageman is supported by Dutch research grants from Marti-Keunig Eckhart Stichting, Anna Foundation and Spinoza Foundation. Job N. Doornberg received unrestricted research grants from the Rene Marti KeuningEckhardt Foundation and the Professor C.N. van Dijk Postdoc Research Award.

\section{Footnotes}

Authors' Contribution: Michiel G.J.S. Hageman and Diederik Meijer are shared first authors based on equal contribution; this study represents a great deal of effort, resources and dedication on the part of the authors in reviewing and comparing the clinical outcomes of proximal humeral fractures, executing an online interobserver reliability study via the science of variation group (www.scienceofvariationgroup.org) and performing statistical analyses; all authors have participated in a material way to at least two of the five elements: study design Job N. Doornberg, David Ring, Michiel G.J.S. Hageman, E. Ph. Steller; gathered data: Michiel G.J.S. Hageman, Diederik Meijer, Sjoerd A. Stufkens; analyzed data: Job N. Doornberg, Michiel G.J.S. Hageman, Diederik Meijer; initial draft: Michiel G.J.S. Hageman, Job N. Doornberg, David Ring; ensured accuracy of data: Job N. Doornberg, Michiel G.J.S. Hageman, Diederik Meijer, E. Ph. Steller, David Ring, Sjoerd A. Stufkens

Conflict of Interest: The authors have no conflict of interest to declare.

\section{References}

1. Handoll $\mathrm{HH}$, Ollivere BJ. Interventions for treating proximal humeral fractures in adults. Cochrane Database Syst Rev. 2010(12):CD000434. doi: 10.1002/14651858.CD000434.pub2. [PubMed: 21154345].

2. Zyto K. Non-operative treatment of comminuted fractures of the proximal humerus in elderly patients. Injury. 1998;29(5):349-52. [PubMed: 9813677].

3. Handoll $\mathrm{HH}$, Ollivere BJ, Rollins KE. Interventions for treating proximal humeral fractures in adults. Cochrane Database Syst Rev. 2012;12:CD000434. doi: 10.1002/14651858.CD000434.pub3. [PubMed: 23235575].

4. Rangan A, Handoll H, Brealey S, Jefferson L, Keding A, Martin BC, et al. Surgical vs nonsurgical treatment of adults with displaced fractures of the proximal humerus: the PROFHER randomized clinical trial. JAMA. 2015;313(10):1037-47. doi: 10.1001/jama.2015.1629. [PubMed: 25756440].

5. Guy P, Slobogean GP, McCormack RG. Treatment preferences for displaced three- and four-part proximal humerus fractures. $J$ Orthop Trauma. 2010;24(4):250-4. doi: 10.1097/BOT.0b013e3181bdc46a. [PubMed: 20335760].

6. Fialka C, Stampfl P, Arbes S, Reuter P, Oberleitner G, Vécsei V. Primary hemiarthroplasty in four-part fractures of the proximal humerus: randomized trial of two different implant systems. J Shoulder Elbow Surg. 2008;17(2):210-5.

7. Hirschmann MT, Fallegger B, Amsler F, Regazzoni P, Gross T. Clinical longer-term results after internal fixation of proximal humerus fractures with a locking compression plate (PHILOS).J Orthop Trauma. 2011;25(5):286-93.

8. Olerud P, Ahrengart L, Ponzer S, Saving J, Tidermark J. Hemiarthroplasty versus nonoperative treatment of displaced 4-part proximal humeral fractures in elderly patients: a randomized controlled trial. J Shoulder Elbow Surg. 2011;20(7):1025-33. doi: 10.1016/j.jse.2011.04.016. [PubMed: 21783385].

9. Hodgson S. Proximal humerus fracture rehabilitation. Clin Orthop Relat Res. 2006;442:131-8. [PubMed:16394751].

10. Fjalestad T, Hole MO, Jorgensen JJ, Stromsoe K, Kristiansen IS. Health and cost consequences of surgical versus conservative treatment for a comminuted proximal humeral fracture in elderly patients. Injury. 2010;41(6):599-605. doi: 10.1016/j.injury.2009.10.056. [PubMed: 19945102].

11. Olerud P, Ahrengart L, Ponzer S, Saving J, Tidermark J. Internal fixation versus nonoperative treatment of displaced 3-part proximal humeral fractures in elderly patients: a randomized controlled trial.J Shoulder Elbow Surg. 2011;20(5):747-55. doi: 10.1016/j.jse.2010.12.018. [PubMed: 21435907].

12. Neer C2. Displaced proximal humeral fractures. I. Classification and evaluation. J Bone Joint Surg Am. 1970;52(6):1077-89. [PubMed: 5455339].

13. Constant CR. [Assessment of shoulder function]. Orthopade. 1991;20(5):289-94. [PubMed: 1745538].

14. Fialka C, Oberleitner G, Stampfl P, Brannath W, Hexel M, Vecsei V. Modification of the Constant-Murley shoulder score-introduction of the individual relative Constant score Individual shoulder assessment. Injury. 2005;36(10):1159-65. doi:10.1016/j.injury.2004.12.023. [PubMed: 16214462].

15. Gunther CM, Burger A, Rickert M, Crispin A, Schulz CU. Grip strength in healthy caucasian adults: reference values. J Hand Surg Am. 2008;33(4):558-65. doi: 10.1016/j.jhsa.2008.01.008. [PubMed: 18406961].

16. Hudak PL, Amadio PC, Bombardier C. Development of an upper extremity outcome measure: the DASH (disabilities of the arm, shoulder and hand) [corrected]. The Upper Extremity Collaborative Group (UECG). Am J Ind Med. 1996;29(6):602-8. doi: 10.1002/(SICI)10970274(199606)29:6<602::AID-AJIM4>3.0.CO;2-L. [PubMed: 8773720]. 
17. Cuijpers P, Smit F, Voordouw I, Kramer J. Outcome of cognitive behaviour therapy for minor depression in routine practice. Psychol Psychother. 2005;78(Pt 2):179-88. doi: 10.1348/147608304X22391. [PubMed: 16004697].

18. Osman A, Barrios FX, Gutierrez PM, Kopper BA, Merrifield T, Grittmann L. The Pain Catastrophizing Scale: further psychometric evaluation with adult samples. J Behav Med. 2000;23(4):351-65. [PubMed: 10984864].

19. Severeijns R, van den Hout MA, Vlaeyen JW, Picavet HS. Pain catastrophizing and general health status in a large Dutch community sample. Pain. 2002;99(1-2):367-76. [PubMed: 12237216].

20. Radloff LS. The CES-D scale a self-report depression scale for research in the general population. Appl Psychol Meas. 1977;1(3):385-401.

21. Aaronson NK, Muller M, Cohen PD, Essink-Bot ML, Fekkes M, Sanderman R, et al. Translation, validation, and norming of the Dutch language version of the SF-36 Health Survey in community and chronic disease populations. J Clin Epidemiol. 1998;51(11):1055-68. [PubMed:
9817123].

22. Brunner F, Sommer C, Bahrs C, Heuwinkel R, Hafner C, Rillmann P, et al. Open reduction and internal fixation of proximal humerus fractures using a proximal humeral locked plate: a prospective multicenter analysis. J Orthop Trauma. 2009;23(3):163-72. doi: 10.1097/BOT.ob013e3181920e5b. [PubMed:19516088].

23. Sudkamp N, Bayer J, Hepp P, Voigt C, Oestern H, Kaab M, et al. Open reduction and internal fixation of proximal humeral fractures with use of the locking proximal humerus plate. Results of a prospective, multicenter, observational study. J Bone Joint Surg Am. 2009;91(6):1320-8. doi: 10.2106/JBJS.H.00006. [PubMed:19487508].

24. Konrad G, Bayer J, Hepp P, Voigt C, Oestern H, Kaab M, et al. Open reduction and internal fixation of proximal humeral fractures with use of the locking proximal humerus plate. Surgical technique.J Bone Joint Surg Am. 2010;92 Suppl 1 Pt 1:85-95. doi: 10.2106/JBJS.I.01462. [PubMed: 20194347]. 